\title{
O que é mais vantajoso para o município de Patos de Minas: manter próprio ou terceirizar o transporte público escolar rural? Um estudo de caso
}

\begin{abstract}
Geovane Camilo Santos Especialização em Planejamento e Gestão Tributária pelo Centro Universitário de Patos de Minas - UNIPAM Professor da Faculdade Patos de Minas - FPM Rua Major Gote, 1408. Centro. Patos de Minas/MG. CEP: 38700-000 E-mail: geovane_camilo@yahoo.com.br

Maria Auxiliadora Godinho Oliveira Especialização em Controladoria, Auditoria e Perícia Contábil pelo Centro Universitário de Patos de Minas - UNIPAM Superintendente do Instituto de Previdência Municipal de Patos de Minas E-mail:conta.dora@hotmail.com

Edvard Trajano Junior Especialização em Contabilidade, Controladoria e Auditoria em Organizações do Setor Público pelo Centro Universitário de Patos de Minas - UNIPAM Servidor público/contador na Prefeitura de Patos de Minas E-mail: edvard.trajano@terra.com.br
\end{abstract}

\section{RESUMO}

O objetivo principal deste artigo é verificar a modalidade mais vantajosa para a Prefeitura Municipal de Patos de Minas: manter próprio ou terceirizar o serviço de transporte público rural. Justifica-se por gerar conhecimento sobre custos com transporte escolar rural; aumentar o número de trabalhos empíricos publicados sobre o setor público e apresentar à população como os recursos arrecadados estão sendo empregados. O estudo tem abordagem quantitativa, quanto aos objetivos é uma pesquisa descritiva e por estudar a prefeitura patense é caracterizado como um estudo de caso. Os valores utilizados até o dia 30 de junho de 2013 são reais e a partir do dia 01 de julho de 2013 são estimados. $\mathrm{Na}$ análise foram utilizadas quatro rotas de transportes; duas próprias e duas terceirizadas, sendo em cada uma delas dois veículos, uma kombi e um ônibus. Os valores referentes aos veículos terceirizados foram disponibilizados pelo setor de compras e licitação da prefeitura. Quanto aos valores referentes aos transportes próprios estes foram apurados mediante cálculos realizados utilizando dados repassados pelo setor de transporte daquele ente público. A apuração foi separada em: custos fixos e custos variáveis. Os resultados encontrados demonstram que o transporte escolar rural terceirizado para o veículo ônibus é mais vantajoso para o município, e manter próprio o transporte com o veículo kombi é melhor, considerando o fator quilômetro unitário rodado. 
O que é mais vantajoso para o município de Patos de Minas: manter próprio ou terceirizar o transporte público escolar rural? Um estudo de caso Geovane Camilo Santos, Maria Auxiliadora Godinho Oliveira, Edvard Trajano Junior

Palavras-chave: Contabilidade. Custo. Transporte escolar.

\title{
What is more advantageous to Patos de Minas City: maintains its rural school public transport private or outsources it? A case study
}

\begin{abstract}
The main objective of this article is to investigate the most advantageous method to Patos de Minas Municipality: outsources or maintains its own rural public transport service. This work is warranted on generating knowledge about rural school transportation costs; increasing the number of empirical studies published for the public sector and presenting to the population how their resources are being employed. The approach is quantitative, for objectives, it is a descriptive research, and as it studies the Patense City hall, it is featured as a case study. It is fundamental emphasizing that, until June 30, 2013 the values are real and from the first of July 2013, they are estimated. Four transportation routes were used in the analysis, two private and two subcontractors, in each of them there are two vehicles, a van and a bus. The values for the outsourced vehicles were made available by the municipal office purchase and bid sector. As for the figures related to their own means of transport, these were determined by calculations performed using data transferred by that public entity transport sector. The investigation was divided into: fixed costs and variable costs. The results show the bus outsourced rural school transport is more advantageous to the city, and if the van is kept as its private transport vehicle it will be better, considering the unitary kilometer driven factor.
\end{abstract}

Keywords: Accounting. Cost. School transport.

\section{INTRODUÇÃO}

A Contabilidade pública tradicional tem-se prestado à mensuração, ainda que conceitualmente falha, de eventos econômicos passados das entidades, tendo como foco principal a execução orçamentária e financeira, deixando de evidenciar atos e fatos que afetam ou podem afetar o patrimônio.

A Contabilidade sob o enfoque orçamentário e financeiro contraria o Princípio da Entidade que reconhece o patrimônio como objeto da Contabilidade e afirma a autonomia patrimonial, a necessidade da diferenciação de um patrimônio particular no universo dos patrimônios existentes, independentemente de pertencer a uma pessoa, 
O que é mais vantajoso para o município de Patos de Minas: manter próprio ou terceirizar o transporte público escolar rural? Um estudo de caso Geovane Camilo Santos, Maria Auxiliadora Godinho Oliveira, Edvard Trajano Junior

um conjunto de pessoas, uma sociedade ou instituição de qualquer natureza ou finalidade, com ou sem fins lucrativos.

Como reconhecimento da importância do equilíbrio fiscal, a aprovação da Lei de Responsabilidade Fiscal (LRF) iniciou o processo de mudança na Gestão Pública e na Contabilidade Pública do Brasil. Observa-se que está surgindo uma nova forma de Administração Pública, a gerencial e, por consequência, de controle e informações confiáveis para tomada de decisões, sob um enfoque prospectivo, técnico, como atividade de vanguarda na vigilância e orientação.

Com estas mudanças a informação contábil se tornará mais transparente, além de facilitar o trabalho dos órgãos de controle e a harmonização de procedimentos contábeis e atendimento dos Princípios Fundamentais de Contabilidade e das Normas Brasileiras de Contabilidade Aplicadas ao Setor Público (NBCASP). A Contabilidade será uma ferramenta efetiva de decisão política, econômica e social.

Atualmente o Brasil passa por um período de transição entre o modelo tradicional (com foco na prestação de contas, tomada de contas e execução orçamentária) para o novo modelo (ferramenta de gestão e informação) de Contabilidade Pública. O caminho a percorrer é longo e uma das grandes dificuldades é a escassa bibliografia sobre o tema. A Contabilidade Pública brasileira está se adequando as Normas Brasileiras de Contabilidade Aplicadas ao Setor Público, e quando isso ocorrer ela estará adequada ao padrão internacional.

Para que estas mudanças se realizem é necessário o uso de ferramentas eficazes de trabalho, principalmente ótimos Sistemas Informatizados de Contabilidade, capazes de gerar todas as informações e relatórios em conformidade com a legislação em vigor.

A previsão da depreciação, a utilização do regime de competência para receitas e despesas, a contabilização dos bens de uso comum, os relatórios dos fluxos de caixas e a instituição do subsistema de custos, são as principais mudanças que a Contabilidade Pública sofre atualmente. (CORREIA et al., 2012). Curi et al. (2012) destacam que um dos temas relevantes para o setor público é a gestão de custos, pois 
O que é mais vantajoso para o município de Patos de Minas: manter próprio ou terceirizar o transporte público escolar rural? Um estudo de caso Geovane Camilo Santos, Maria Auxiliadora Godinho Oliveira, Edvard Trajano Junior

é necessário ter conhecimento do valor do serviço público que é oferecido à sociedade. Portanto, o controle dos custos sempre foi necessário em todas as empresas, mas atualmente isto se torna fundamental, seja no setor privado ou público. Na área pública torna-se ainda mais relevante, por se tratar de dinheiro público que deve retornar em forma de benefícios à própria sociedade.

Sendo assim, este estudo objetivou levantar os custos que a prefeitura de Patos de Minas tem com duas rotas do transporte escolar rural, sendo uma de ônibus e outra de kombi, e comparar com o valor despendido com duas outras rotas terceirizadas adotando os mesmos critérios e verificar qual modalidade é mais vantajosa para o transporte escolar rural.

O estudo se justifica por gerar conhecimento para o setor público, no que tange aos custos relacionados ao setor de transporte escolar rural; por contribuir com a área de custos aplicados ao setor público que possui poucos estudos empíricos; e pelo fato de que os recursos utilizados pertencem a população e esta deve estar ciente da destinação do seu próprio dinheiro.

Este estudo está estruturado em cinco partes iniciando por esta introdução; o referencial teórico, abordando os seguintes temas: "Contabilidade Pública, Transparência na Gestão Pública, Contabilidade de Custos e Custos no Setor Público"; a metodologia; a análise dos resultados e as considerações finais.

\section{REFERENCIAL TEÓRICO}

Esta seção apresenta o referencial teórico deste artigo, com os temas: Contabilidade Pública, Transparência na Gestão Pública, Contabilidade de Custos e Custos no Setor Público.

\subsection{Contabilidade Pública}

A Contabilidade Pública é a ciência responsável pelo registro, controle e estudo dos atos e fatos administrativos e econômicos operados no patrimônio público da 
O que é mais vantajoso para o município de Patos de Minas: manter próprio ou terceirizar o transporte público escolar rural? Um estudo de caso Geovane Camilo Santos, Maria Auxiliadora Godinho Oliveira, Edvard Trajano Junior

entidade. Este conjunto possibilita a geração de informações, variações e resultados auferidos pela administração e pelos usuários. (ANDRADE, 2002). A NBCT 16.1 acrescenta que ela tem a finalidade de aplicar os conceitos de Contabilidade e as normas contábeis que visem controlar o patrimônio do setor público. (CFC, 2008). As Normas Brasileiras de Contabilidade Aplicadas ao Setor Público (NBCASP) abrangem todas as entidades do setor público e estas devem observar as normas e técnicas aplicáveis a estas entidades.

O artigo 85 da lei ํㅜ 4.320 de 1964 define que a Contabilidade Pública tem a função de organizar a execução orçamentária, o conhecimento de composição patrimonial e a determinação dos custos referentes dos serviços industriais. (BRASIL, 1964). Em seu art. 101, a lei menciona que "os resultados gerais do exercício serão demonstrados no Balanço Orçamentário, no Balanço Financeiro, no Balanço Patrimonial, na Demonstração das Variações Patrimoniais, além de outros quadros demonstrativos." (BRASIL, 1964, p. 2763).

A diferença entre a Contabilidade Pública e a Contabilidade Societária é o foco na gestão, pois a primeira não visa o lucro e sim o estudo dos resultados, das receitas arrecadadas e das despesas executadas, demonstrando se houve ou não eficiência nos gastos. (CONTE, 2012).

O setor público deve ser auto-sustentável sendo, portanto, fundamental o conhecimento e o controle de custos. Logo, é necessário um sistema que permita medir os custos para ajudar nas tomadas de decisões. (CORREIA et al., 2012).

\subsection{Transparência na Gestão Pública}

A Constituição Federal de 1988 em seu artigo 37 dispõe que "a administração pública direta, indireta, ou fundacional, de qualquer dos Poderes da União, dos Estados, do Distrito Federal e dos Municípios obedecerá aos princípios da legalidade, impessoalidade, moralidade e publicidade." (BRASIL, 1988). 
O que é mais vantajoso para o município de Patos de Minas: manter próprio ou terceirizar o transporte público escolar rural? Um estudo de caso Geovane Camilo Santos, Maria Auxiliadora Godinho Oliveira, Edvard Trajano Junior

A transparência dos atos, fatos e da gestão pública é um dos pilares de sustentabilidade da democracia. Portanto, não há democracia sem transparência na gestão pública. (CONTROLADORIA GERAL DA UNIÃO - CGU, 2012).

No passado, a prestação de contas era assunto, apenas, dos tribunais. A LRF estabeleceu um processo de accountability (obrigação de prestar contas) quando exigiu publicidade, participação popular e demonstrações fiscais, com periodicidade menor que um ano, publicado até 30 dias após o encerramento de cada bimestre e composto de vários demonstrativos. (CASTRO, 2008, p. 289).

A Lei $n^{\circ} 12.527$ promulgada em 18 de novembro de 2011 dispõe em seu artigo $5^{\circ}$ que "é dever do Estado garantir o direito de acesso à informação, que será franqueada, mediante procedimentos objetivos e ágeis, de forma transparente, clara e em linguagem de fácil compreensão." (BRASIL, 2011).

Portanto, a prestação de contas é de suma importância, pois esclarece aos usuários (sociedade) da informação como ocorre a administração de seu dinheiro. Dentre estas informações a mais essencial é a prestação das contas no setor público.

\subsection{Contabilidade de Custos}

A contabilidade de Custos inicialmente surgiu para apropriar os valores dos bens que a indústria produz. Ao longo do tempo passou a ser utilizada apenas para mensurar os estoques e os resultados. E hoje os empresários sabem e começam a dar maior importância ao controle e gestão de custos para o sucesso da empresa. (CORREIA et al., 2012).

Os custos são as parcelas de materiais necessários à produção. Eles são ativados passando a incorporar os estoques dos produtos em elaboração e acabados (VICECONTI; NEVES, 2012). Martins (2010) acrescenta que é um gasto para a produção de bens e serviços, e que passa a incorporar o valor final destes.

De acordo Cruz e Platt Neto (2007, p. 41) o sistema de custos 
O que é mais vantajoso para o município de Patos de Minas: manter próprio ou terceirizar o transporte público escolar rural? Um estudo de caso Geovane Camilo Santos, Maria Auxiliadora Godinho Oliveira, Edvard Trajano Junior

Compreende o modelo e tipo de processo para organizar as informações de custos, oriundas das diversas áreas da entidade jurídica, recursos humanos, logística, econômica, financeira, contábil, operacional (produção, vendas, gerência) etc., apurando, assim, dados e informações para que a contabilidade de custos possa gerar relatórios e outras informações que sirvam para o processo decisório.

Os custos fixos são aqueles que existem independentes de haver ou não a produção, portanto, não são considerados como custos para produzir e sim como despesas, que são encerradas contra o resultado do exercício. Os custos variáveis estão sujeitos a alteração de valores, em função do volume de produção da empresa, portanto, eles aumentam à medida que fabrica maior quantidade de produtos. (VICECONTI; NEVES, 2012).

Correia et al. (2012) enfatizam que com a aprovação da portaria 828/11 todos os entes federativos, inclusive os municípios terão que adotar os procedimentos contábeis patrimoniais. A portaria é muito importante devido a alguns fatores: cada ente federativo possui 90 dias a partir do prazo inicial estabelecido para publicar, por meios eletrônicos e nos Tribunais de Contas os procedimentos contábeis patrimoniais e específicos que serão utilizados na prática, e os que serão realizados posteriormente deverão vir apresentados num cronograma. Um dos principais procedimentos adotados são os subsistemas de custos. (SILVA, 2011).

Segundo Conte (2012), com a convergência às Normas da Contabilidade Aplicada ao Setor Público o que provavelmente trouxe maior impacto é a implantação do sistema de custos na administração pública, pois assim é possível evidenciar o resultado econômico nos serviços públicos.

\subsection{Custos no Setor Público}

Os custos no setor público estão preocupados com o desempenho dos serviços prestados pelas entidades públicas, enquanto que no setor privado preocupam-se com a avaliação de estoques e com a apuração de lucros. (CONTE; MIRANDA, 2012). As 
O que é mais vantajoso para o município de Patos de Minas: manter próprio ou terceirizar o transporte público escolar rural? Um estudo de caso Geovane Camilo Santos, Maria Auxiliadora Godinho Oliveira, Edvard Trajano Junior

apurações de custos no setor público são obrigatórias, de forma restrita, desde a promulgação da lei no 4.320 de 1964, para as empresas públicas industriais. (SOUZA; DURIGON, 2012). E o registro de custos passou a ser obrigatório para toda a administração pública federal, com o Decreto-Lei no 200 de 1967. (BRASIL, 1967).

A Lei Complementar 101 de 2000 reforçou o disposto nas leis anteriores, que a Administração Pública deve possuir um sistema de custos, que lhe permite avaliar e acompanhar a gestão orçamentária, financeira e patrimonial. (BRASIL, 2000).

E a Resolução CFC no 1.366/11 aprovou a obrigação dos custos na área pública, uma vez que apresenta os sistemas de informações de custos no setor público. A presente resolução conceitua, define o objeto e os objetivos das regras básicas para mensurar e evidenciar os custos nas entidades públicas. (CFC, 2011).

Com a aprovação da Resolução $n^{0}$ 1.366/11, é possível verificar que houve aumento na rapidez e na segurança do gerenciamento e consolidação dos dados obtidos pela instituição. Neste sentido, quando a gestão de custos acompanha o desempenho das atividades da entidade, verifica que ela auxilia a controladoria a direcionar informações que possibilitem a implementação de programas gerenciais mais eficazes para que as metas estratégicas sejam atingidas. (SOUZA; DURIGON, 2012).

O objetivo de um subsistema de custos é a coleta, o processamento e a apuração dos custos das gestões políticas públicas (CORREIA et al., 2012). Os sistemas de custos permitem a entidade pública controlar a ação governamental, em que o resultado é obtido pela análise da eficiência da utilização dos recursos disponíveis aos órgãos para a execução dos programas de governo. (ROSA, 2011).

O setor público necessita dos conhecimentos de custos para alocar de forma eficiente os recursos. As gestões que não conhecem e não sabem utilizar os custos mostram sinais de ineficiências. (ALONSO, 1999). É fundamental conhecer os custos de uma entidade pública, pois assim os gestores terão melhores condições de tomar decisões de forma mais acertada e gerindo melhor o dinheiro público, permitindo a entidade ter sua saúde financeira preservada. (CONTE, 2012). O autor aduz que o conhecimento sobre os custos que a entidade pública possui é fundamental, 
O que é mais vantajoso para o município de Patos de Minas: manter próprio ou terceirizar o transporte público escolar rural? Um estudo de caso Geovane Camilo Santos, Maria Auxiliadora Godinho Oliveira, Edvard Trajano Junior

principalmente, em casos de decisões sobre produzir ou terceirizar o produto/serviço, permitindo que os custos da entidade sejam menores, sem prejudicar a qualidade dos mesmos. Conte e Miranda (2012) argumentam que as maiores dificuldades encontradas nas administrações públicas são: a implantação do sistema de custos, e a conscientização da necessidade de apurar com exatidão os custos.

A maioria dos gestores públicos não sabe se as ações disponibilizadas à sociedades são ou não bem sucedidas, pois os mesmos desconhecem se algum corte que realizam em alguma despesa é essencial ou supérfluo. (BRASIL, 2011). Se o ente público não possuir um controle do sistema de custos adequado, a apuração de resultados, a produção de informações econômico-financeiras e os relatórios de desempenho serão ineficientes. (CORREIA et al., 2012). Logo, é necessário que as entidades públicas tenham um bom controle e planejamento de custos, entretanto estas informações nas entidades públicas brasileiras são escassas, o que não permite medir com eficiência os serviços prestados à sociedade. (CONTE, 2012).

\section{METODOLOGIA}

O presente estudo pode ser classificado como uma pesquisa descritiva e quantitativa, além de ser caracterizado como um estudo de caso.

A pesquisa descritiva tem como principal objetivo descrever as características de uma população ou fenômeno ou estabelecer a relação entre as variáveis. Esta forma de pesquisa caracteriza pela utilização de técnicas padronizadas para coleta de dados. (GIL, 1999).

Também se emprega a pesquisa quantitativa que é caracterizada pelo aproveitamento de instrumentos estatísticos para coleta e tratamento dos dados (RICHARDSON, 1999; BEUREN, 2006). Richardson (1999) acrescenta que esta forma de pesquisa descreve a complexidade de um problema, analisa a interação de algumas variáveis, além de compreender e classificar os processos dinâmicos de grupos sociais. 
O que é mais vantajoso para o município de Patos de Minas: manter próprio ou terceirizar o transporte público escolar rural? Um estudo de caso Geovane Camilo Santos, Maria Auxiliadora Godinho Oliveira, Edvard Trajano Junior

O estudo de caso é um estudo exaustivo de um ou poucos objetos para permitir conhecimento amplo e detalhado (GIL, 1999). Para Ruiz (1989) este é uma formulação real de uma investigação que é planejada e estruturada por meio das normas metodológicas de determinada ciência para aprofundar no tema proposto. Em conformidade com Yin (2005), o estudo de caso é a investigação empírica de um fenômeno real, principalmente quando estes estão bem definidos.

A coleta de dados foi realizada nos setores específicos da Prefeitura Municipal de Patos de Minas (MG). Os valores referentes aos veículos terceirizados foram disponibilizados pelo setor de compras e licitação da prefeitura. Quanto aos valores referentes aos transportes próprios estes foram apurados mediante cálculos realizados utilizando dados repassados pelo setor de transporte daquele ente público.

A primeira rota terceirizada é a de número 38 , realizada por um veículo kombi, que comporta 15 passageiros com o seguinte itinerário: Serra do Queiroz - Ribeirão da Cota - Escola Municipal Maria Inez Rubinger de Queiroz Rodrigues. Nesta o veículo faz o transporte em apenas um horário - manhã - percorrendo um total de $95 \mathrm{~km} / \mathrm{dia}$.

A segunda rota é a de número 02 realizada por um ônibus com capacidade para 31 passageiros com o seguinte itinerário: Acampamento 02 de novembro - Baleiros Escola Estadual Juca Mandu. E o trecho por ele percorrido é de 270 quilômetros, em três horários manhã/tarde/noite.

As rotas de veículos próprios são as de números 06 e 40 . A rota de número 06 é realizada por uma kombi, que comporta 15 passageiros com o seguinte itinerário: Serra da Quina - Santa Maria - Fazenda do Armando - Escola Municipal F. de Paula - Bom Sucesso - Santa Maria. Nesta o veículo roda 130 quilômetros/dia, apenas no período da manhã.

A rota de número 40 é realizada por um ônibus com capacidade para 31 passageiros e perfazendo o seguinte itinerário: Fazenda do Virgílio - Paraíso Fazenda Santa Terezinha - Fazenda Geraldo da Luz - Escola Estadual Juca Mandu. O veículo percorre diariamente $120 \mathrm{~km}$ em dois horários manhã/tarde. 
O que é mais vantajoso para o município de Patos de Minas: manter próprio ou terceirizar o transporte público escolar rural? Um estudo de caso Geovane Camilo Santos, Maria Auxiliadora Godinho Oliveira, Edvard Trajano Junior

Em razão do ano letivo contar com 200 dias, o cálculo da coluna "Valor estimado até 31 de dezembro de 2013" constante das tabelas 5, 6, 7 e 8 foi apurado tomando como base o "Valor até 30 de junho 2013". Do referido valor utilizou-se a seguinte fórmula: Valor até 30 de junho 2013 + Valor até 30 de junho $2013 \times 7 \%$. O percentual de $7 \%$ é a diferença entre $46,5 \%$ e $53,5 \%$, uma vez que o objetivo é encontrar $100 \%$.

\section{RESULTADOS}

Nesse estudo utilizou-se quatro rotas de transporte escolar, sendo duas próprias e duas terceirizadas, ambas feitas por uma Kombi e um ônibus. Os valores das rotas terceirizadas foram encontrados junto ao setor de compras e licitação da prefeitura e são apresentados na tabela 1.

Tabela 1 - Custo do transporte terceirizado

\begin{tabular}{|c|c|c|}
\hline Rota & 38 & 02 \\
\hline Dias letivos & 200 & 200 \\
\hline Km/dia & 95 & 270 \\
\hline Km/ano & 19.000 & 54.000 \\
\hline Custo por $\mathrm{km}$ & $\mathrm{R} \$ 2,27$ & $\mathrm{R} \$ 2,01$ \\
\hline Custo por ano & $\mathrm{R} \$ 43.130,00$ & $\mathrm{R} \$ 108.540,00$ \\
\hline
\end{tabular}

Fonte: Elaborado pelos autores mediante dados fornecidos pelo setor de compras e licitação da prefeitura.

$\mathrm{Na}$ Tabela 1 percebe-se que o ônibus é o veículo que tem a maior quantidade de quilometragem rodada/dia, pois o mesmo percorre $270 \mathrm{~km} / \mathrm{dia}$, enquanto a kombi apenas $95 \mathrm{~km} / \mathrm{dia}$. Considerando o ano letivo conter 200 dias, então ao final do ano a kombi percorre 19.000 quilômetros, enquanto o ônibus 54.000.

Ainda de acordo com a Tabela 1 verifica-se que a kombi apresenta um custo unitário de $R \$ 2,27$ por quilômetro e com o percurso final de $19.000 \mathrm{~km}$, significando que a prefeitura despende o valor de $\mathrm{R} \$ 43.130,00$ no fim do exercício. Quanto ao veículo de porte grande o custo por quilômetro foi valorado em $R \$ 2,01$ e com o 
O que é mais vantajoso para o município de Patos de Minas: manter próprio ou terceirizar o transporte público escolar rural? Um estudo de caso Geovane Camilo Santos, Maria Auxiliadora Godinho Oliveira, Edvard Trajano Junior

percurso total de 54.000 quilômetros o custo final aos cofres públicos é de $R \$$ 108.540,00.

$\mathrm{Na}$ apuração dos custos finais com os veículos próprios, no município de Patos de Minas se analisam os custos fixos e variáveis. Os custos fixos uma vez apurados são mantidos por todo o ano.

Os custos fixos da kombi são apresentados na Tabela 2:

Tabela 2 - Custo fixo do transporte escolar próprio - Kombi

\begin{tabular}{|c|c|}
\hline 1 - COMPOSIÇÃO DO PREÇO FIXO & \\
\hline Custo Fixo & Total \\
\hline Depreciação & $\mathrm{R} \$ 3.990,00$ \\
\hline Seguro do Casco & $\mathrm{R} \$ 792,36$ \\
\hline Vistoria & $\mathrm{R} \$ 130,00$ \\
\hline DPVAT & $\mathrm{R} \$ 246,48$ \\
\hline Custo de Oportunidade & $\mathrm{R} \$ 2.394,00$ \\
\hline Custo Fixo do Veículo & $\mathrm{R} \$ 7.552,84$ \\
\hline Custo Fixo com pessoal & $R \$ 14.718,62$ \\
\hline Salários & $\mathrm{R} \$ 8.648,16$ \\
\hline Encargos Sociais e Trabalhistas & $\mathrm{R} \$ 2.517,14$ \\
\hline Previdência $19,9 \%$ sobre salários & $\mathrm{R} \$ 1.720,98$ \\
\hline FASERV $6 \%$ & $\mathrm{R} \$ 518,89$ \\
\hline 1/3 Férias & $\mathrm{R} \$ 240,23$ \\
\hline Previdência $19,9 \%$ sobre $1 / 3$ férias & $\mathrm{R} \$ 47,81$ \\
\hline $13^{\circ}$ Salário & $\mathrm{R} \$ 720,68$ \\
\hline Previdência $19,9 \%$ sobre $13^{\circ}$ Salário & $\mathrm{R} \$ 143,42$ \\
\hline Férias Prêmio $60 \%$ ano & $\mathrm{R} \$ 432,41$ \\
\hline Previdência $19,9 \%$ sobre Férias Prêmio & $\mathrm{R} \$ 86,05$ \\
\hline Vale Alimentação & $R \$ 2.160,00$ \\
\hline CUSTO FIXO TOTAL DO VEÍCULO & $R \$ 22.271,46$ \\
\hline
\end{tabular}

Fonte: elaborado pelos autores mediante dados fornecidos pela prefeitura.

Os custos fixos que a prefeitura desembolsou com a Kombi foram divididos em duas formas: custo fixo do veículo e custo fixo com pessoal.

O custo fixo com veículo é composto pela depreciação, seguro do casco, vistoria, DPVAT e custo de oportunidade, o que gerou um valor de $R \$ 7.552,84$, e o percentual 
O que é mais vantajoso para o município de Patos de Minas: manter próprio ou terceirizar o transporte público escolar rural? Um estudo de caso Geovane Camilo Santos, Maria Auxiliadora Godinho Oliveira, Edvard Trajano Junior

de $33,91 \%$ do total. O custo fixo com pessoal envolve o salário do motorista e respectivos encargos na folha de pagamento, o que resulta no valor de $R \$ 14.718,62$, representando $66,09 \%$ do valor total dos custos fixos. Dessa forma, os custos fixos representam um desembolso total aos cofres públicos de Patos de Minas no valor de $\mathrm{R} \$ 22.271,46$.

$\mathrm{Na}$ tabela é possível verificar que os encargos sobrecarregam o valor final dos custos fixos, uma vez que estes representam $17,10 \%$ dos custos fixos com pessoal.

A Prefeitura Municipal de Patos de Minas tem uma particularidade quanto aos recolhimentos, pois disponibiliza alíquota de $6 \%$ sobre o total da folha para o Fundo de Saúde do Servidor Público de Patos de Minas (FASERV).

Os custos fixos que o município teve com o ônibus adotam os mesmos critérios da Kombi, ou seja, divididos em custo fixo do veículo e custo fixo pessoal (Tabela 3). 
O que é mais vantajoso para o município de Patos de Minas: manter próprio ou terceirizar o transporte público escolar rural? Um estudo de caso Geovane Camilo Santos, Maria Auxiliadora Godinho Oliveira, Edvard Trajano Junior

Tabela 3 - Custo fixo do transporte escolar próprio - ônibus

\begin{tabular}{|c|c|}
\hline 1 - COMPOSIÇÃO DO PREÇO FIXO & \\
\hline Custo Fixo & Total \\
\hline Depreciação & $\mathrm{R} \$ 21.000,00$ \\
\hline Seguro do Casco & $\mathrm{R} \$ 871,92$ \\
\hline Vistoria & $\mathrm{R} \$ 180,00$ \\
\hline Documentação Veículo & $\mathrm{R} \$ 246,48$ \\
\hline Custo de Oportunidade & $\mathrm{R} \$ 12.600,00$ \\
\hline Custo Fixo do Veículo & $\mathbf{R} \$ 34.898,40$ \\
\hline Custo Fixo & $\mathbf{R} \$ 17.042,91$ \\
\hline Salário Motorista & $\mathrm{R} \$ 10.248,72$ \\
\hline Encargos Sociais e Trabalhistas & $\mathrm{R} \$ 2.983,00$ \\
\hline Previdência $19,9 \%$ sobre salários & $\mathrm{R} \$ 2.039,50$ \\
\hline FASERV $6 \%$ & $\mathrm{R} \$ 614,92$ \\
\hline 1/3 Férias & $\mathrm{R} \$ 284,69$ \\
\hline Previdência $19,9 \%$ sobre $1 / 3$ férias & $\mathrm{R} \$ 56,65$ \\
\hline 13ํㅗalário & $\mathrm{R} \$ 854,06$ \\
\hline Previdência $19,9 \%$ sobre $13^{\circ}$ Salário & $\mathrm{R} \$ 169,96$ \\
\hline Férias Prêmio $60 \%$ ano & $\mathrm{R} \$ 512,44$ \\
\hline Previdência 19,9\% sobre Férias Prêmio & $\mathrm{R} \$ 101,97$ \\
\hline Vale Alimentação & $\mathrm{R} \$ 2.160,00$ \\
\hline CUSTO FIXO TOTAL DO VEÍCULO & $\mathbf{R} \$ 51.941,31$ \\
\hline
\end{tabular}

Fonte: elaborado pelos autores mediante dados fornecidos pela prefeitura.

Os custos fixos com o ônibus alcançaram a quantia de $R \$ 51.941,31$, deste valor $\mathrm{R} \$ 34.898,40$ (67,19\%) relativos a custo fixo com veículo e $\mathrm{R} \$ 17.042,91$ (32,81\%,) com custo fixo com pessoal, deste último $17,50 \%$ destinados aos encargos trabalhistas.

Para a apuração dos custos variáveis foram realizados cálculos utilizando valores reais praticados pelo setor de compras e licitação até o dia 30 de junho de 2013.

Nos cálculos da previsão dos custos que aquele ente público terá até 31 de dezembro de 2013 foi considerada a quantidade de dias que os veículos percorreram 
O que é mais vantajoso para o município de Patos de Minas: manter próprio ou terceirizar o transporte público escolar rural? Um estudo de caso Geovane Camilo Santos, Maria Auxiliadora Godinho Oliveira, Edvard Trajano Junior

no ano em estudo. Até o dia 30 de junho de 2013 contam-se 93 dias letivos, ou seja, $46,50 \%$ do total analisado e até 31 de dezembro de 2013107 dias, representando $53,50 \%$. Este percentual foi observado na apuração do custo com o transporte escolar rural no período de 01 de julho de 2013 a 31 de dezembro de 2013 (Tabela 4).

Tabela 4 - Porcentagem de dias letivos até 30 de junho de 2013 e porcentagem de dias letivos do dia 01 de julho de 2013 a 31 de dezembro de 2013

\begin{tabular}{|c|c|}
\hline Total de Dias Letivos & 200 \\
\hline Dias letivos até 30 de junho de 2013 & 93 \\
\hline Dias letivos de 01 de julho de 2013 até 31 de dezembro de 2013 & 107 \\
\hline$\%$ de dias letivos até 30 de junho de 2013 & $46,50 \%$ \\
\hline$\%$ de dias letivos de 01 de julho de 2013 até 31 de dezembro de 2013 & $53,50 \%$ \\
\hline
\end{tabular}

Fonte: elaborado pelos autores mediante dados fornecidos pela prefeitura.

Os custos variáveis são rateados em combustível e peças/manutenção, sendo estes últimos subdivididos em: suspensão, motor, elétrica, freio, acessórios, transmissão, funilaria e produtos. Os custos variáveis da kombi são apresentados na tabela 5 . 
O que é mais vantajoso para o município de Patos de Minas: manter próprio ou terceirizar o transporte público escolar rural? Um estudo de caso Geovane Camilo Santos, Maria Auxiliadora Godinho Oliveira, Edvard Trajano Junior

Tabela 5 - Custo variável do transporte escolar próprio - Kombi

\begin{tabular}{|c|c|c|c|}
\hline CUSTO VARIÁVEL & $\begin{array}{l}\text { Valor até } 30 \text { de } \\
\text { junho } 2013\end{array}$ & $\begin{array}{l}\text { Valor estimado de } \\
01 \text { de julho de } \\
2013 \text { até } 31 \text { de } \\
\text { dezembro de } 2013\end{array}$ & Total \\
\hline Combustível & $\mathrm{R} \$ 2.743,89$ & $\mathrm{R} \$ 2.935,96$ & $\mathrm{R} \$ 5.679,85$ \\
\hline Pecas/manutenção & $\mathrm{R} \$ 4.144,03$ & $\mathrm{R} \$ 4.434,11$ & $\mathrm{R} \$ \mathbf{8 . 5 7 8 , 1 4}$ \\
\hline Suspensão & $R \$ 1.359,00$ & $R \$ 1.454,13$ & $\mathrm{R} \$ 2.813,13$ \\
\hline Motor & $\mathrm{R} \$ 581,01$ & $\mathrm{R} \$ 621,68$ & $\mathrm{R} \$ 1.202,69$ \\
\hline Elétrica & $\mathrm{R} \$ 1.030,02$ & $\mathrm{R} \$ 1.102,12$ & $\mathrm{R} \$ 2.132,14$ \\
\hline Freio & $\mathrm{R} \$ 488,00$ & $\mathrm{R} \$ 522,16$ & $\mathrm{R} \$ 1.010,16$ \\
\hline Acessórios & $\mathrm{R} \$ 98,00$ & $\mathrm{R} \$ 104,86$ & $R \$ 202,86$ \\
\hline Transmissão & $\mathrm{R} \$ 445,00$ & $\mathrm{R} \$ 476,15$ & $\mathrm{R} \$ 921,15$ \\
\hline Funilaria & $\mathrm{R} \$ 88,00$ & $\mathrm{R} \$ 94,16$ & $\mathrm{R} \$ 182,16$ \\
\hline Produtos & $\mathrm{R} \$ 55,00$ & $\mathrm{R} \$ 58,85$ & $\mathrm{R} \$ 113,85$ \\
\hline CUSTO VARIÁVEL & $\mathrm{R} \$ 6.887,92$ & R\$ 7.370,07 & R\$ 14.257,99 \\
\hline
\end{tabular}

Fonte: elaborado pelos autores mediante dados fornecidos pela prefeitura.

Examinando-se os dados da Tabela 5, percebe-se que o custo variável que 0 ente público obterá com a kombi ao longo do ano de 2013 se situa no patamar de $R \$$ 14.257,99. Extraindo $6.887,92$ que foi gasto até 30 de junho de 2013, houve uma estimativa em relação aos valores apresentados na Tabela 4, já que a tabela 5 apresenta o valor de $R \$ 7.370,07$. Do total dos valores estimados, $R \$ 2.935,96$ são gastos com combustíveis e $R \$ 4.434,11$ com peças/manutenção.

Percebe-se que do total dos gastos a maior parcela, ou seja, $60,16 \%$ é destinada ao pagamento de peças/manutenção, enquanto que apenas $39,84 \%$ com combustível. Dentre os custos com peças/manutenção os gastos mais dispendiosos são suspensão e parte elétrica, respectivamente, que juntas são responsáveis pelo desembolso de $R \$$ $4.945,27(57,65 \%)$ dos referidos custos.

O montante de custos variáveis do transporte escolar próprio ônibus consta na Tabela 6. 
O que é mais vantajoso para o município de Patos de Minas: manter próprio ou terceirizar o transporte público escolar rural? Um estudo de caso Geovane Camilo Santos, Maria Auxiliadora Godinho Oliveira, Edvard Trajano Junior

Tabela 6 - Custo variável do transporte escolar próprio - ônibus

\begin{tabular}{|c|c|c|c|}
\hline \multicolumn{4}{|c|}{2 - COMPOSIÇÃO DE CUSTO VARIÁVEL } \\
\hline CUSTO VARIÁVEL & $\begin{array}{c}\text { Valor até } 30 \text { de } \\
\text { junho } 2013\end{array}$ & \begin{tabular}{|c|} 
Valor estimado de \\
01 de julho de 2013 \\
até 31 de dezembro \\
de 2013 \\
\end{tabular} & Total \\
\hline Combustível & $R \$ 7.415,06$ & $\mathrm{R} \$ \mathbf{7 . 9 3 4 , 1 1}$ & $R \$ 15.349,17$ \\
\hline Pecas/manutenção & $R \$ 1.465,00$ & $R \$ 1.567,55$ & $R \$ 3.032,55$ \\
\hline Suspensão & $\mathrm{R} \$ 237,00$ & $\mathrm{R} \$ 253,59$ & $\mathrm{R} \$ 490,59$ \\
\hline Motor & $\mathrm{R} \$ 828,00$ & $\mathrm{R} \$ 885,96$ & $\mathrm{R} \$ 1.713,96$ \\
\hline Acessórios & $\mathrm{R} \$ 400,00$ & $\mathrm{R} \$ 428,00$ & $\mathrm{R} \$ 828,00$ \\
\hline CUSTO VARIÁVEL & $\mathrm{R} \$ \mathbf{8 . 8 8 0 , 0 6}$ & $R \$ 9.501,66$ & $R \$ 18.381,72$ \\
\hline
\end{tabular}

Fonte: elaborado pelos autores mediante dados fornecidos pela prefeitura.

Observando a Tabela 6, verifica-se que o valor desembolsado com custo variável - veículo ônibus - representa um total de $R \$ 18.381,72$, sendo que $R \$ 15.349,17$, ou seja, $83,50 \%$ gasto com combustível, enquanto que $R \$ 3.032,55(16,50 \%)$ gasto com peças/manutenção.

Os gastos até 30 de junho 2013 somam o valor de $R \$ 8.880,06$, sendo $R \$$ $7.415,06$ com combustível e $\mathrm{R} \$ 1.465,00$ com peças/manutenção, enquanto que os gastos estimados geram o valor de $R \$ 9.501,66$, com a participação de $R \$ 7.934,11$ para os custos com combustível e apenas $R \$ 1.567,55$ com peças/manutenção.

Percebe-se, portanto, uma disparidade entre os custos variáveis da kombi e do ônibus, enquanto o primeiro tem maiores gastos com peças/manutenção, o segundo com combustível. Um fator preponderante desta ocorrência pode ser devido ao fato do veículo médio ter condições precárias, o que torna a manutenção mais cara. De outro lado, o fator significativo é que o veículo ônibus percorre maior quilometragem e, portanto, seu gasto com combustível, em comparação com o outro veículo é maior.

Os custos fixos e variáveis relacionados com a Kombi podem ser observados na Tabela 7. 
O que é mais vantajoso para o município de Patos de Minas: manter próprio ou terceirizar o transporte público escolar rural? Um estudo de caso Geovane Camilo Santos, Maria Auxiliadora Godinho Oliveira, Edvard Trajano Junior

Tabela 7 - Custo fixo e variável do transporte escolar próprio - Kombi

\begin{tabular}{|c|c|c|c|}
\hline 3 - CUSTO UNITÁRIO TOTAL & $\begin{array}{c}\text { Valor até 30 de } \\
\text { junho 2013 }\end{array}$ & $\begin{array}{c}\text { Valor estimado até 31 de } \\
\text { dezembro de 2013 }\end{array}$ & Total \\
\hline Preço Variável & $\mathrm{R} \$ 6.887,92$ & $\mathrm{R} \$ 7.370,07$ & $\mathrm{R} \$ 14.257,99$ \\
\hline Preço Fixo Unitário & & & $\mathrm{R} \$ 22.271,46$ \\
\hline PREÇO UNITÁRIO TOTAL & $\mathbf{R} \mathbf{6 . 8 8 7 , 9 2}$ & $\mathbf{R} \mathbf{7 . 3 7 0 , 0 7}$ & $\mathbf{R} \mathbf{3 6 . 5 2 9 , 4 5}$ \\
\hline
\end{tabular}

Fonte: elaborado pelos autores mediante dados fornecidos pela prefeitura.

Em termos de custos fixos e variáveis ao longo do período em análise, o veículo médio apresentou um custo total de $R \$ 36.529,45$, sendo $60,97 \%$ com custos fixos, ou seja, $R \$ 22.271,46$, enquanto que os custos variáveis somam $R \$ 14.257,99$, portanto, $39,03 \%$.

Até 30 junho 2013 os custos variáveis atingiram $R \$ 6.887,92$. Os custos variáveis estimados para o período de 01 de julho de 2013 a 31 de dezembro de 2013 geraram a previsão de um desembolso de $\mathrm{R} \$ 7.370,07$.

Os custos fixos e variáveis com a utilização do ônibus constam na Tabela 8.

Tabela 8 - Custo fixo e variável do transporte escolar próprio - Ônibus

\begin{tabular}{|c|c|c|c|}
\hline 3 - CUSTO UNITÁRIO TOTAL & $\begin{array}{c}\text { Valor até 30 de } \\
\text { junho 2013 }\end{array}$ & $\begin{array}{c}\text { Valor estimado até 31 de } \\
\text { dezembro de 2013 }\end{array}$ & Total \\
\hline Preço Variável & $\mathrm{R} \$ 8.880,06$ & $\mathrm{R} \$ 9.501,66$ & $\mathrm{R} \$ 18.381,72$ \\
\hline Preço Fixo Unitário & & & $\mathrm{R} \$ 51.941,31$ \\
\hline PREÇO UNITÁRIO TOTAL & $\mathbf{R} \$ \mathbf{8 . 8 8 0 , 0 6}$ & $\mathbf{R} \$ \mathbf{9 . 5 0 1 , 6 6}$ & $\mathbf{R} \mathbf{7 0 . 3 2 3 , 0 3}$ \\
\hline
\end{tabular}

Fonte: elaborado pelos autores mediante dados fornecidos pela prefeitura.

Considerando os custos fixos e variáveis ao longo do período em análise, o maior veículo (ônibus) apresentou um custo total de $\mathrm{R} \$ 70.323,03$; deste montante $73,86 \%$ com custos fixos, ou seja, $\mathrm{R} \$ 51.941,31$, enquanto que os custos variáveis geraram um dispêndio de $\mathrm{R} \$ 18.381,72$, portanto, $26,14 \%$.

Até 30 junho 2013 os custos variáveis atingiram $R \$ 8.880,06$, e os custos variáveis estimados para o período de 01 de julho de 2013 a 31 de dezembro de 2013 geraram um desembolso de $\mathrm{R} \$ 9.501,66$. 
O que é mais vantajoso para o município de Patos de Minas: manter próprio ou terceirizar o transporte público escolar rural? Um estudo de caso Geovane Camilo Santos, Maria Auxiliadora Godinho Oliveira, Edvard Trajano Junior

Nas tabelas apresentadas foi possível demonstrar que em ambos os veículos os gastos que geraram os maiores desembolsos foram com os custos fixos. Isto ocorre devido, principalmente, ao alto valor que é despendido com os salários dos motoristas e encargos previdenciários como verificado nas Tabelas 2 e 3.

Os custos unitários referentes ao uso da Kombi e do ônibus podem ser visualizados na Tabela 9.

Tabela 9 - Custo unitário Kombi e ônibus

\begin{tabular}{|c|c|c|}
\hline & Kombi & Ônibus \\
\hline Quantidade Km diários & 130 & 120 \\
\hline Quantidade de dias & 200 & 200 \\
\hline Total km ano & 26.000 & 24.000 \\
\hline Custo total & $\mathrm{R} \$ 36.529,45$ & $\mathrm{R} \$ 70.323,03$ \\
\hline Custo total variável & $\mathrm{R} \$ 14.257,99$ & $\mathrm{R} \$ 18.381,72$ \\
\hline Custo total fixo & $\mathrm{R} \$ 22.271,46$ & $\mathrm{R} \$ 51.941,31$ \\
\hline Custo unitário & $\mathrm{R} \$ 1,40$ & $\mathrm{R} \$ 2,93$ \\
\hline
\end{tabular}

Fonte: elaborado pelos autores mediante dados fornecidos pela prefeitura.

$\mathrm{Na}$ Tabela 9 percebe-se que para o veículo kombi pertencente ao município o preço unitário por quilômetro rodado é de $R \$ 1,40$, e em contrapartida para o veículo terceirizado é de $R \$ 2,27$, sendo assim, foi apurada uma diferença de $R \$ 0,87$ por quilômetro a maior caso o referido veículo seja terceirizado.

$\mathrm{Na}$ mesma tabela observa-se que para o ônibus pertencente ao município o preço unitário por quilômetro rodado é de $\mathrm{R} \$ 2,93$, enquanto que para o terceirizado o valor é de $R \$ 2,01 \mathrm{Km} /$ rodado, apurando-se, assim, uma diferença de 0,92/km a maior, caso o ente público opte por manter o serviço próprio.

Um fator que majorou os custos fixos dos veículos se refere a que os servidores públicos municipais recebem a verba "Férias Prêmio" o que certamente interfere no valor final. Outro fator que influenciou o resultado foi à utilização do custo de oportunidade, que segundo Pereira e Oliveira (1999, p. 414) "é o valor de um determinado recurso em seu melhor uso alternativo. Representa o custo da escolha de 
O que é mais vantajoso para o município de Patos de Minas: manter próprio ou terceirizar o transporte público escolar rural? Um estudo de caso Geovane Camilo Santos, Maria Auxiliadora Godinho Oliveira, Edvard Trajano Junior

uma alternativa em detrimento de outra capaz de proporcionar um maior benefício, ou seja, é o custo da melhor oportunidade a que se renuncia quando da escolha de uma alternativa.".

Este custo, portanto, é importante nas tomadas de decisões, pois envolve a escolha de alternativas. Ele é o benefício que se obtém em uma tomada de decisão, onde se considera a melhor alternativa que envolve os recursos.

\section{CONSIDERAÇÕES FINAIS}

O presente estudo demonstrou os custos que a prefeitura de Patos de Minas deverá disponibilizar, no ano de 2013, com o transporte escolar rural. Diante dos resultados encontrados procedeu-se uma comparação do que é mais vantajoso para o município: terceirizar ou manter própria esta modalidade de transporte.

Os custos foram realizados em quatro rotas; duas terceirizadas e duas próprias, sendo que em ambas utilizou-se uma kombi e um ônibus.

Os custos foram divididos em custos fixos e custos variáveis. Os resultados apresentados mostraram que o valor gasto com os custos fixos é maior em relação aos custos variáveis no uso dos dois veículos. Dentre os custos fixos percebe-se que os relativos ao veículo ônibus se apresentam superiores em relação ao veículo kombi. Nas Tabelas 2 e 3 observa-se uma curiosidade: enquanto o veículo kombi exige maior desembolso no custo fixo com pessoal, o veículo ônibus absorve valores superiores gastos com ele próprio.

Nos custos variáveis percebe-se uma divergência entre os dois veículos: enquanto que os custos com peças/manutenção da kombi tem maior representatividade, no ônibus o maior dispêndio é com combustível, sendo o principal fator a quilometragem total percorrida.

Ao comparar os valores pagos por quilômetro rodado entre a terceirização do veículo kombi com os valores gastos com a própria frota, verifica-se que a locação do veículo é mais onerosa para o município. De forma diferente acontece com os custos 
O que é mais vantajoso para o município de Patos de Minas: manter próprio ou terceirizar o transporte público escolar rural? Um estudo de caso Geovane Camilo Santos, Maria Auxiliadora Godinho Oliveira, Edvard Trajano Junior

por quilômetro rodado do veículo ônibus, pois manter própria a rota é que se tornou mais oneroso.

O presente estudo apresenta similaridade com o estudo de Conte (2012), no qual o autor demonstrou que o transporte escolar próprio mantido pela prefeitura de São Domingos do Sul (RS) é mais oneroso em $88 \%$ do valor terceirizado.

Com os resultados apurados nesse estudo, é possível aos administradores do município de Patos de Minas tomarem decisões e direcionar o dinheiro púbico em outras áreas prioritárias para a população.

Para estudos posteriores recomendam-se, no mínimo pesquisas em três pontos fundamentais: análise de todas as rotas que a instituição pública oferece à população, tanto as terceirizadas quanto as próprias; utilização de métodos de custos para estimar o impacto nos custos finais com a comparação entre os custos fixos e variáveis com o custeio por absorção e, por último, desenvolver um trabalho que possibilite demonstrar o percentual gasto com o transporte escolar dos valores repassados aos municípios pela esfera estadual e federal.

\section{REFERÊNCIAS}

ALONSO, Marcos. (1999). Custos no serviço público. Revista do Serviço Público. Ano 50 , n. 1, p. 37-63.

ANDRADE, Nilton de Aquino. (2002). Contabilidade pública na gestão municipal. São Paulo: Atlas.

BEUREN. Ilse Maria. (2006). Como elaborar trabalhos monográficos em contabilidade: Teoria e Prática. (3 ed.). São Paulo: Atlas.

BRASIL. Lei no 4.320 de 17 março de 1964. Estatui Normas Gerais de Direito Financeiro para elaboração e controle dos orçamentos e balanços da União, dos Estados, dos Municípios e do Distrito Federal. Diário Oficial da União, Poder Executivo, Brasília, DF, 17 mar. 1964. Seção 1, p. 2745.

. Decreto-Lei no 200, de 25 de fevereiro de 1967. Dispõe sobre a organização da Administração Federal, estabelece diretrizes para a Reforma Administrativa e dá outras 
O que é mais vantajoso para o município de Patos de Minas: manter próprio ou terceirizar o transporte público escolar rural? Um estudo de caso Geovane Camilo Santos, Maria Auxiliadora Godinho Oliveira, Edvard Trajano Junior

providências. Diário Oficial da União, Poder Executivo, Brasília, DF, 27 fev. 1967. Seção 1 , p. 4, suplemento.

. Constituição da República Federativa do Brasil. (1988). Diário Oficial da União, Poder Legislativo, Brasília, DF, 5 out. Seção 1.

Lei Completar no 200, de 4 de maio de 2000. Estabelece normas de finanças públicas voltadas para a responsabilidade na gestão fiscal e dá outras providências. Diário Oficial da União, Poder Legislativo, Brasília, DF, 5 maio, 2000. Seção 1, p. 1.

. Lei $n^{\circ}$ 12.527, de 18 de novembro de 2011. Regula o acesso a informações

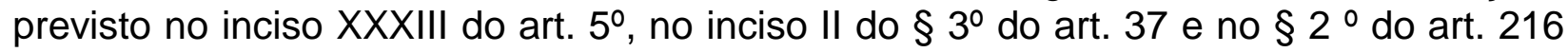
da Constituição Federal; altera a Lei oㅡ 8.112, de 11 de dezembro de 1990; revoga a Lei no 11.111, de 5 de maio de 2005, e dispositivos da Lei no 8.159 , de 8 de janeiro de 1991; e dá outras providências. Diário Oficial da União, Poder Legislativo, Brasília, DF, 18 nov. de 2011. Edição Extra.

Secretaria do Tesouro Nacional. (2011). Manual de Contabilidade Aplicado ao Setor Público: aplicado à União, aos Estados, ao Distrito Federal e aos Municípios. (4 ed.). Brasília: Secretaria do Tesouro Nacional, Coordenação-Geral de Contabilidade.

CASTRO, Domingos Poubel de. (2008). Auditoria e Controle Interno na Administração Pública: Evolução de Controle Interno no Brasil - Do Código de Contabilidade de 1922 até a Criação da CGU em 2003 - Guia para Atuação das Auditorias e Organização dos Controles Internos nos Estados, Municípios e ONGS. São Paulo: Atlas.

CFC - Conselho Federal de Contabilidade. Resolução CFC no. 1.128/08 - Aprova a NBC T 16.1 - Conceituação, Objeto e Campo de Aplicação. Diário Oficial da União, Brasília, DF, 25 nov. 2008. Seção 1.

. Resolução CFC no. 1.366/11 - Aprova a NBC T 16.11 - Sistema de Informação de Custos do Setor. Diário Oficial da União, Brasília, DF, 12 dez. 2011. Seção 1.

CONTE, Nelson Carlos. (2012). Sistema de informação de custos na administração pública: um estudo no serviço de transporte escolar no Município de São Domingos do Sul - RS. In: XIX Congresso Brasileiro de Custos, Gramado. Anais... São Leopoldo: Associação Brasileira de Custos.

CONTE, Nelson Carlos, MIRANDA, Wagner Tadeu. (2012). Sistema de custos aplicado ao setor público: um estudo sobre a maturidade da gestão contábil nos municípios associados à AMPLA - Associação dos Municípios do Planalto Médio - com relação às Normas Brasileiras de Contabilidade Aplicadas ao Setor Público e ao Manual de 
O que é mais vantajoso para o município de Patos de Minas: manter próprio ou terceirizar o transporte público escolar rural? Um estudo de caso Geovane Camilo Santos, Maria Auxiliadora Godinho Oliveira, Edvard Trajano Junior

Contabilidade Aplicado ao Setor Público. In: XIX Congresso Brasileiro de Custos, Gramado. Anais... São Leopoldo: Associação Brasileira de Custos.

CONTROLADORIA GERAL DA UNIÃO. (2012). Acesso à Informação Pública: Uma Introdução à Lei $n^{\circ} 12.527$, de 18 de novembro de 2011. Brasília. Disponível em: <http://www.acs.ufpr.br/cgu.pdf>. Acesso em: 19/maio/2013.

CORREIA, Rosana Aparecida Almeida et al. (2012). Sistema de Custos Municipal: Desafios, Obstáculos e Percepção no Caso do Município de Vilhena - RO. In: XIX Congresso Brasileiro de Custos, Gramado. Anais... São Leopoldo: Associação Brasileira de Custos.

CRUZ, Flávio da; PLATT NETO, Orion Augusto. (2007). Contabilidade de custos para entidades estatais: metodologia e casos simulados. Belo Horizonte: Fórum.

CURI, Maria Aparecida. (2012). Mensuração e alocação de custos no setor público de acordo com as atribuições da controladoria: Caso de uma Instituição Federal de Ensino Superior. In: XIX Congresso Brasileiro de Custos. Gramado. Anais... São Leopoldo: Associação Brasileira de Custos.

GIL, Antonio Carlos. (1999). Métodos e técnicas de pesquisa social. (5 ed.). São Paulo: Atlas.

MARTINS, Eliseu. (2010). Contabilidade de custos. (10 ed.). São Paulo: Atlas.

PEREIRA, Carlos Alberto; OLIVEIRA, Antônio Benedito Silva. (2001). Preço de transferência: uma aplicação do conceito de custo de oportunidade. In: CATELLI, Armando (Org.). Controladoria: uma abordagem da gestão econômica GECON. São Paulo: Atlas.

RICHARDSON, Roberto J. (1999). Pesquisa Social: métodos e técnicas. São Paulo: Atlas.

ROSA, Maria Berenice. (2011). Contabilidade do Setor Público - de acordo com as inovações das normas brasileiras de contabilidade técnicas aplicadas ao setor público. Contém as mudanças das práticas contábeis vigentes, conforme MCASP editado pela STN. São Paulo: Atlas.

RUIZ, João Álvaro. (1989). Metodologia científica: guia para eficiência nos estudos. (2 ed.). São Paulo: Atlas.

SÁ, Antônio Lopes de. (2008). Fundamentos da Contabilidade Geral: Com Referência à Reforma das Sociedades por Ações - Lei 11.638/07. (3 ed.). Curitiba: Juruá. 
O que é mais vantajoso para o município de Patos de Minas: manter próprio ou terceirizar o transporte público escolar rural? Um estudo de caso Geovane Camilo Santos, Maria Auxiliadora Godinho Oliveira, Edvard Trajano Junior

SILVA, Lino Martins da. (2011). Contabilidade Governamental: um enfoque administrativo da nova contabilidade pública. (9 ed.). São Paulo: Atlas.

SOUZA, Marcos Antônio de; DURIGON, Almir Rodrigues. (2012). Controladoria em instituição pública de ensino superior: percepção do seu papel sob a ótica dos gestores da Unemat. In: XIX Congresso Brasileiro de Custos, Gramado. Anais... São Leopoldo: Associação Brasileira de Custos.

VICECONTI, Paulo; NEVES, Silvério das. (2012). Contabilidade Básica. (15 ed.). São Paulo: Saraiva.

YIN, Robert K. (2005). Estudo de caso: planejamento e métodos. (3 ed.). Porto Alegre: Bookman.

Data de Submissão: 03/12/2013

Data de Aceite: 17/03/2014 